\title{
A Simulation Study for Waiting Line Systems by $\mathrm{C}$ Programming
}

\author{
Ozer O]GP Ш
}

\begin{abstract}
Simulation is a method that using especially waiting line systems. In this study, a simulation study has made for waiting line systems by $\mathrm{C}$ programming. The particular queue will be a place where customers are waiting for service behind each other. For the purpose of this study, a simulation in $\mathrm{C}$ language is created in order to simulate the aforementioned queue system. With this simulation, it is aimed to increase customers' satisfaction by decreasing service cost, and to increase the quality of service with minimum waiting time. Considering alternative solutions, the optimal system is obtained to ensure economical stability between the interests of the customers and the management.
\end{abstract}

Keywords - C programming language, Cash desks system, Simulation, Waiting line system.

\section{INTRODUCTION}

$\mathrm{S}$ imulation is a method that provides acting an original system by means of a mathematical model which is essential for using computer [3]. Simulation is used in various spaces. One of the most useful spaces is queue system. This system can be called waiting line system. Today this system occurs in many states such as ticket queue, medicine queue, salary queue, bank queue or shopping queue and alternative solutions which are related with problem of queue aspect of people satisfaction are investigated.

History of Simulation starts with China war's games which are called "Weich" and comes from 5000 years ago. It continues until 1780s [1]. To considering simulation as a method of experimentation and aim of scientific runs across 1944. It goes on a study about atom bomb which is prepared by approach of simulation of Von Neumann and Slam during Second World War. This study includes simulation of probability problems which are related with random neutron matching diffusion in fissile materiel.

A simulation method which is called "Monte Carlo" becomes popular by studies of Fermi, Von Neumann and Slam and it is used for solving theoretical problems by using computers by many mathematicians, physicists and statisticians [2]. Simulation improves as a management tool by coming business computers and using them by combining them in 1950s. Specialized languages of computers are developed in 1960s for considering extended size problems effectively [1].

Ozer OZDEMIR is with the Department of Statistics, Eskisehir Technical University Eskisehir 26470 TURKEY (corresponding author to provide phone: 902223350580-804668; e-mail: ozerozdemir@eskisehir.edu.tr).
Many problems which are not understand directly and are not possible to produce experimentally are started to solve by using method of simulation over computers after 1960. This approach is used for solving problem as a quite common scientific approach [2].

Simulation programs which are written for considering ranking of conditions from invention which was inserted queue are developed in 1980s [1].

Simulation studies which can be useful for these kinds of systems provide improving system, solving problems in the system and increasing satisfaction of manager, employee and customer in a certain economical stability.

This study is prepared for improving queue systems which are caused problems between people and producing a study for finding alternative solutions for problems.

A market's cash desk system which has only one queue is considered by using $\mathrm{C}$ programming in this study. Creating the most suitable system is purposed aspect of management and customer. All good and bad ways of the present system are denoted after simulation study and suggestions are given for improving bad ways of the present system. In short, this study is prepared for improving queue systems which are caused big problems between people and finding alternative solutions for problems. Simulations of some distributions which are used in this study will be denoted before simulation application.

There are several papers about simulation studies such as given in [8-17].

\section{SimUlation OF UNIFORM RANDOM VARIABLE}

The probability density function of random variable $X$ which is distributed uniformly in $[a, b]$ is given as

$$
f(x)=\left\{\begin{array}{cc}
\frac{1}{b-a} & \text { for } a \leq x \leq b \\
0 & \text { for } x<a \text { or } x>b
\end{array} .\right.
$$

The cumulative distribution function is: 


$$
F(x)=\left\{\begin{array}{cc}
0 & \text { for } x<a, \\
\frac{x-a}{b-a} & \text { for } a \leq x<b \\
1 & \text { for } x \geq b
\end{array}\right.
$$

The expected value is

$$
E(x)=\frac{a+b}{2},
$$

and variance is

$$
V(x)=\frac{(b-a)^{2}}{12}
$$

Suppose that $\mathrm{U}$ is an uniform variable in $[0,1]$.

$$
F(x)=U \quad \text { for } a \leq x<b,
$$

Solution of this equation is:

$$
X=a+(b-a) U
$$

properly [4-7].

\section{SimUlATION OF EXPONENTIAL RANDOM VARIABLE}

If $F(x)=1-e^{-x}$ then $F^{-1}(U)$ can be found by solution of equation $1-e^{-x}=u$ according to variable $x$.

$$
X=-\log (1-U)
$$

Hence $Y=F^{-1}(U)=-\log (1-U)$, whose expected value is 1 , is distributed exponential for $U$ which is uniform variable in $[0,1]$.

$$
(1-U) \rightarrow[0,1]
$$

is uniform [4-7].

\section{Short Example For Application}

$t$ shows the time that is between arrivals of customers for a barbershop. $t$ indicates exponential distribution and its mean is:

$$
E(t)=\frac{1}{\lambda}
$$

So its probability density function is:

$$
f(t)=\lambda e^{-\lambda t} \quad \text { for } t>0,
$$

We can find random sample of $t$ from $f(t)$.

Distribution function is:

$$
\begin{aligned}
& F(t)=\int_{0}^{t} \lambda e^{-\lambda x} d x=1-e^{-\lambda t} \text { for } t>0 \\
& F(t)=R \Rightarrow t=F^{-1}(R) \\
& 1-e^{-\lambda t}=R \Rightarrow t=-\frac{1}{\lambda} \ln (1-R) \\
& \Rightarrow t=-\frac{1}{\lambda} \ln R \text { for } R[0,1]
\end{aligned}
$$

is uniform number.

For example, when $\lambda=4$ customers come for service in an hour and $R=0.9$, time is:

$$
\begin{aligned}
t & =-\frac{1}{4} \ln (1-0.9)=0.577 \text { hour } \\
& =34.5 \text { minutes }
\end{aligned}
$$

until another customer comes. $R$ should choose random. Table of random numbers is used for this choice [4-7].

\section{RESULTS AND DISCUSSION}

Two cash desks system which are called "Express Cash DeskMaximum Five Products" are going to consider in one of the most famous market in Turkey. Customers take service by using one queue from these cash desks and when customers come for service, they take service from free cash desk. If two cash desks are free then customers choose first cash desk. Mean of time which is between arrivals of customers for these cash desks will be defined by assuming that it corresponds with exponential distribution. Also it will be defined by assuming that time of cashiers' working corresponds with uniform distribution. Customers are serviced according to a principle that is "First service is given to customer who comes firstly". Purpose of simulation is finding performance measures which can be listed as

1. Mean usage time of two cash desks;

2. Mean number of customers who queue(Mean length of queue);

3. Mean waiting time of a customer who queues. 
Mean of time which is between arrivals of customers for two cash desks and time of cashiers' working will be defined by considering system for 30 minutes for finding these performance measures. For that reason, this cash desk system is considered for 30 minutes and a table which is below is prepared (Between 17:00 and 17:30 o'clock).

Cash desk system considers customers who come for service in 30 minutes. 42 customers come for service in this time. Mean of time which is between arrivals of customers for two cash desks is found (M.A.C.);

$$
\begin{aligned}
\text { M.A.C. } & =(17: 29: 40-17: 00: 17) /(42-1) \\
& =43 \text { seconds. }
\end{aligned}
$$

Mean and standard deviation of time of cashiers' working are calculated.

For first cashier;

$$
\begin{aligned}
& \mu_{1}=61 \text { Seconds } \\
& \sigma_{1}=21 \text { Seconds }
\end{aligned}
$$

For second cashier;

$$
\begin{aligned}
& \mu_{2}=83 \text { Seconds } \\
& \sigma_{2}=27 \text { Seconds }
\end{aligned}
$$

Application can be changed as below after these reasons.

Two cash desks system which are called "Express Cash Desk-Maximum Five Products" are going to consider in one of the most famous market in Turkey. Customers take service by using one queue from these cash desks and when customers come for service, they take service from free cash desk. If two cash desks are free then customers choose first cash desk. Mean of time which is between arrivals of customers for these cash desks will be defined by assuming that it corresponds with exponential distribution whose mean is 43 seconds. Customers are serviced according to a principle that is "First service is given to customer who comes firstly". Purpose of simulation is finding performance measures which are identified as:

1. Mean usage time of two cash desks;

2. Mean number of customers who queue(Mean length of queue);

3. Mean waiting time of a customer who queues.

First cashier gives service between $40(61-21=40)$ and $82(61+21=82)$ seconds by uniform distribution.

Second cashier gives service between $56(83-27=56)$ and $110(83+27=110)$ seconds by uniform distribution.
Mean of time which is between arrivals of customers is exponential distribution and its mean is 43 seconds according to data. Time of service is $40-82$ seconds for first cashier and 56-110 seconds for second cashier.

$p$ denotes time which is between arrivals of customers, $q_{1}$ denotes time of service for first cashier and $q_{2}$ denotes time of service for second cashier for uniform random number $(0 \leq R \leq 1)$.

These values will be calculated with:

$$
p=-43 \ln (R) \text { seconds for } 0 \leq R \leq 1,
$$

by using equation

$$
p=-\frac{1}{\lambda} \ln R
$$

and

$$
q_{1}=40+42 R \text { seconds for } 0 \leq R \leq 1 \text {, }
$$

$$
q_{2}=56+54 R \text { seconds for } 0 \leq R \leq 1 \text {, }
$$

by using equation

$$
q=a+(b-a) R .
$$

Performance measures are achieved by given data, formulates and a program which is written by using "Microsoft Visual Studio C++ 6.0" (Number of customers is given 1000, if this number is increased, we can obtain better results).

Mean usage time of first cash desk is asked for first performance measure. For answering this question, time that first cashier did not give service subtracts from time that first cashier totally gave service and this result is divided by this total service time. There is similar operation for second cash desk.

Mean number of customers who queue or mean length of queue is asked for second performance measure. For answering this question, total waiting time is divided by simulation time.

Mean waiting time of a customer who queues is asked for third performance measure. For answering this question, total waiting time is divided by number of customers.

When the program which is convenient for problem and data is run, output of the program is obtained.

Last customer comes for service at 17 hours (1000 customers approximately come for service in 17 hours). Maximum length of queue is 2 customers for service. This result is good aspect of management and cashiers who work these cash desks. Because there is no accumulation for queue and there is no customers' dissatisfaction so, cashiers work 
well. We can see from first performance measure that second cashier works more than first cashier but this situation is observed because second cashier works slower than first. Mean length of queue is very small number as 0.08 . Very short queue is occurred obtaining from statistics of maximum length of queue. This result is very important aspect of management. Because management decides to increase or decrease numbers of cash desks according to this result. If it decides to decrease numbers of cash desks, it provides benefit aspect of economical stability but its result can be seen a simulation study again. Results can be obtained according to length of queue after decreasing numbers of cash desks. A good result is seen from statistics of mean waiting time of a customer who queues as mean length of queue. 5.4 seconds is very short for waiting for a service. Consequently, mean waiting time of a customer who queues is appreciated by customers and manager.

\section{CONCLUSIONS}

A market's cash desks system with one queue was considered in this study and results were obtained. 3 performance measures concern with system are obtained after this study. Firstly, mean usage times of both two cash desks are very close each other and these are found approximately $\% 90$. Number of cash desks can be like this according to this result. If number of cash desks is increased, it may get economical burden aspect of management. Secondly, mean length of queue of system which has one queue and two cash desks were simulated. Very short length of queue was obtained as 0.08 customers. Finally, a result which likes second performance measure was found. Mean waiting time of a customer who queues was found 5.4 seconds.

Both customers and manager can be appreciated from these results. These results are indicator that management works well and there is not any problem concern with long queue.

In further studies, various queue systems as bank queue, medicine queue, ticket queue or salary queue can be similarly considered like this study. Systems with many queues can be considered instead of one queue and systems with three or more cash desks can be considered instead of system with two cash desks.

\section{REFERENCES}

[1] A. Behiye, Simulasyon Nedir? [What is Simulation?], Retrieved September 10, 2007, from http://bilgibirikimi.tripod.com/simulasyon.htm,2007.

[2] K. Ozdamar, Bilgisayar ile Benzetim Yöntemleri (Benzetime Girişs), Anadolu U. Fen-Edebiyat F., 1988.

[3] H. Sarıaslan, Sira Bekleme Sistemlerinde Simülasyon(Benzetim) Tekniği, A.Ü.S.B.F. Matb., 1986

[4] A. H. Taha, Operational Research, Prentice-Hall, 2002.

[5] J. Banks, J. S. Carson II, B. L. Nelson, D. M. Nicol, Discrete-event system simulation, Prentice-Hall, 2001.

[6] S. M. Ross, Simulation, Elsevier Inc. 2006.

[7] A. M. Law, W. D. Kelton, Simulation Modeling and Analysis, Mc GrawHill International Editions, 1991

[8] W. L. Winston, Operations Research Applications and Algorithms, PWS - KENT Publishing Company, 1991.
[9] B. Khoshnevis, Discrete Systems Simulation, Mc Graw Hill Inc., 1994.

[10] R. E. Shannon, System Simulation: The Art and Science, Prentice-Hall Inc., 1975.

[11] W. C. Griffin, Queueing; Basic Teory and Aplications, Grid Inc., 1978.

[12] G. S. Fishman, Discrete-Event Simulation-Modeling, Programming and Analysis, Springer-Verlag New York Inc., 2001.

[13] P. Bratley, B. L. Fox, L. E. Schrage, A Guide to Simulation, SpringerVerlag New York Inc., 1987.

[14] J. A. Payne, Introduction to Simulation, Mc Graw-Hill Inc, 1982

[15] F. L. Severance, System Modeling and Simulation-An Introduction, John Wiley and Sons Ltd., 2001.

[16] L. Kosten, Stochastic Theory of Service Systems, Pergoman Pres. Oxford, 1973.

[17] T. K. Shridharbhai, Probability and statistics with reliability, queuing, and computer science applications, Prentice-Hall, 1982.

Ozer Ozdemir was born in Turkey in 1982. He received his B.Sc., M.Sc. and Ph.D. degrees in statistics in the Department of Statistics at Anadolu University, Turkey, respectively in 2005, in 2008 and in 2013. He has worked as a Research Assistant from 2006-2008, as a Lecturer from 2008-2014 and as an Assistant Professor from 2014-2018 in the Department of Statistics at Anadolu University, Turkey. He has worked as an Assistant Professor from 2018 in the Department of Statistics at Eskisehir Technical University, Turkey.

He has published over 70 international conference papers and journals in his research areas. His research interests include Applied Statistics, Simulation, Artificial Neural Networks, Fuzzy Logic, Fuzzy Modeling, Time Series, Computer Programming, Statistical Software and Computer Applications in Statistics.

\section{Creative Commons Attribution License 4.0 (Attribution 4.0 International, CC BY 4.0)}

This article is published under the terms of the Creative Commons Attribution License 4.0 https://creativecommons.org/licenses/by/4.0/deed.en_US 